\title{
Cardiac Structure and Function and Insulin Resistance in Morbidly Obese Patients: Does Superobesity Play an Additional Role?
}

\author{
Francesco Antonini-Canterin $^{a} \quad$ Anca D. Mateescu $^{a}$ Olga Vriz $^{d}$

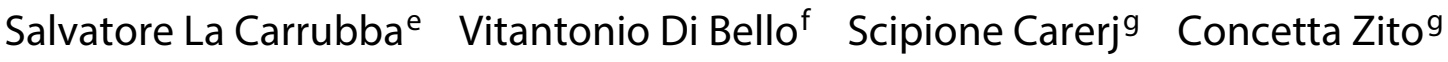 \\ Lina Sparacino $^{a}$ Bernardo Marzano $^{c}$ Cătălin Usurelu ${ }^{a}$ Răzvan Ticulescu ${ }^{a}$ \\ Carmen Ginghinăh $^{\mathrm{h}}$ Gian Luigi Nicolosib $^{\mathrm{b}}$ Bogdan A. Popescu ${ }^{\mathrm{h}}$ \\ ${ }^{a}$ Cardiologia Preventiva e Riabilitativa, ${ }^{b}$ Cardiologia, ARC and ${ }^{C}$ Chirurgia dell'obesità, Azienda Ospedaliera S. Maria \\ degli Angeli, Pordenone, d Cardiologia, Ospedale S. Antonio, San Daniele del Friuli, e Medicina Interna, Ospedale \\ Villa Sofia, Palermo, ${ }^{f}$ Cardiologia, Università di Pisa, Pisa, and ${ }^{9}$ Cardiologia, Università di Messina, Messina, Italy; \\ h'Carol Davila' University of Medicine and Pharmacy, 'Prof. Dr. C.C. Iliescu' Institute of Cardiovascular Diseases, \\ Bucharest, Romania
}

\section{For editorial comment see p. 141}

\section{Key Words}

Obesity . Cardiac remodeling and function .

Insulin resistance

\begin{abstract}
Objective: To evaluate the impact of superobesity, defined as body mass index (BMI) $\geq 50$, on cardiac structure and function. Methods: Using echocardiography, we studied 198 asymptomatic patients (mean age $48 \pm 13$ years, $29.3 \%$ were men) with a $B M I \geq 40$. Insulin resistance was measured using the Homeostasis Model Assessment of insulin resistance (HOMA-IR). Patients were divided into 2 groups: morbidly obese (BMI $\geq 40$ and $<50 ; n=160$ ) and superobese (BMI $\geq 50$; $\mathrm{n}=38)$. Results: There were no significant differences in age, gender, hypertension and diabetes between groups. Superobese patients had higher LV mass $(66.0 \pm 14.7$ vs. $59.9 \pm 11.9$ $\left.\mathrm{g} / \mathrm{m}^{2.7}, \mathrm{p}=0.007\right)$, left ventricular (LV) end-diastolic (33.8 \pm 7.7 vs. $\left.31.5 \pm 7.1 \mathrm{ml} / \mathrm{m}^{2.7}, \mathrm{p}=0.041\right)$ and end-systolic (12.2 \pm 3.6 vs. $10.9 \pm 2.8 \mathrm{ml} / \mathrm{m}^{2.7}, \mathrm{p}=0.016$ ) volumes, left atrial volume (13.8 \pm 4.5 vs. $\left.12.2 \pm 3.9 \mathrm{ml} / \mathrm{m}^{2.7}, \mathrm{p}=0.029\right)$, peak velocity of transmitral flow in early diastole/early diastolic peak
\end{abstract}

myocardial velocity ratio $(9.1 \pm 2.6$ vs. $8.2 \pm 2.2, \mathrm{p}=0.03)$ and HOMA-IR (9.7 \pm 7.3 vs. $7.3 \pm 6.5, p=0.047)$. LV ejection fraction was similar. Conclusions: Superobesity is associated with insulin resistance and a worse impact on cardiac remodeling and LV diastolic function than morbid obesity. Prospective studies are needed to evaluate whether such further classification of morbid obesity could stratify the cardiovascular risk in these patients more accurately.

ㄷ) 2013 S. Karger AG, Basel

\section{Introduction}

Obesity has reached epidemic proportions in both children and adults $[1,2]$. Using the criteria of the National Institutes of Health, obesity is defined as a body mass index (BMI) $\geq 30$ and morbid obesity as a BMI $\geq 40$ [3]. According to the data published by the International

On behalf of the 'Research Group of the Italian Society of Cardiovascular Echography (SIEC)'.

\section{KARGER}

E-Mail karger@karger.com

www.karger.com/crd
(C) 2013 S. Karger AG, Basel

0008-6312/13/1273-0144\$38.00/0
Francesco Antonini-Canterin, MD

Cardiologia Preventiva e Riabilitativa, ARC

Azienda Ospedaliera S. Maria degli Angeli

Via Montereale 24, IT-33170 Pordenone (Italy)

E-Mail antonini.canterin@gmail.com 
Obesity Task Force, $35.5 \%$ of adult men and $35.8 \%$ of adult women are obese [4]. The prevalence of obesity is rising at an alarming rate worldwide, and the prevalence of morbid obesity is increasing at an even steeper rate [5].

Morbid obesity is strongly correlated with the development of risk factors for cardiovascular diseases, including hypertension, type 2 diabetes mellitus, dyslipidemia and metabolic syndrome [6]. It is now recognized that morbid obesity is an important contributor to cardiac and all-cause mortality, that it increases the risk for cardiovascular morbidity and reduces life expectancy $[7,8]$. The fact that obesity is independently associated with cardiac dysfunction is now widely accepted [9].

Morbid obesity is associated with a variety of changes in cardiac structure and function, thought to be mediated by altered hemodynamics and an inflammatory state $[10$, 11]. Obesity produces an increase in total blood volume and cardiac output. This is partially caused by an increased metabolic demand which itself is induced by excess body weight $[12,13]$. Thus, at any given level of activity, the cardiac workload is greater for obese subjects [14]. Ventricular chamber dilation may then result in increased wall stress, which predisposes to an increase in myocardial mass and leading, ultimately, to left ventricular (LV) hypertrophy [15]. Thus, morbid obesity can lead to atrial and ventricular remodeling, both known precursors of atrial and ventricular dysfunction [16].

It has also been apparent for many years that obese individuals tend to be insulin-resistant and become more insulin-sensitive with weight loss $[17,18]$. Therefore, it seems reasonable to hypothesize that insulin resistance may be a key factor for the increased cardiovascular risk of these individuals. It may also precede and contribute to complications of diabetes and hypertension.

The National Institutes of Health Consensus Development Panel agreed on the usage of the term 'super morbid obesity' to designate patients with a BMI $\geq 50$ [19]. Experienced bariatric surgeons have identified this subgroup as presenting special requirements [20]. It could be appropriate to amend the WHO classification by adding a class IV to define the extreme risk category of individuals with $B M I \geq 50$, since this group, the numbers of which are increasing, demonstrates a unique pathophysiology and response to treatment which influence prognosis. Studies have shown that superobesity is associated with a greater burden of obesity-related comorbidities [21]. A massive amount of fat tissue, as is observed in superobesity, could affect cardiac morphology and performance [22]. However, the real impact of superobesity on cardiac structure and function is still largely unknown. Thus, the aim of this study is to evaluate if superobese patients have a worse cardiac remodeling and insulin resistance than morbidly obese patients.

\section{Methods}

\section{Study Population}

We examined 212 asymptomatic consecutive patients with morbid obesity $(\mathrm{BMI} \geq 40)$. All patients were referred to our Preventive Cardiology Department for a comprehensive risk factors screening. We excluded 14 patients due to the poor acoustic window. Patients with known coronary artery disease, history of heart failure or more than mild valvular heart disease were also excluded. Thus, the final population consisted of 198 asymptomatic patients with morbid obesity.

All patients underwent a protocol including clinical history, physical examination, anthropometric measurements (weight, height and waist circumference) and blood tests (12-hour-fasting blood glucose and insulin, total cholesterol, triglycerides, highdensity and low-density lipoprotein (HDL and LDL)-cholesterol according to Friedewald's equation [23]). Standardized questionnaires were used to obtain information about the smoking history, current medications and diagnosis of hypertension and diabetes. Systolic blood pressure $\geq 140 \mathrm{~mm} \mathrm{Hg}$, diastolic blood pressure $\geq 90$ $\mathrm{mm} \mathrm{Hg}$ or using antihypertensive medications were classified as hypertension. Diabetes was defined as the use of hypoglycemic drugs or fasting blood glucose $\geq 126 \mathrm{mg} / \mathrm{dl}$, according to the American Diabetes Association criteria. BMI was calculated as body weight divided by height squared. Metabolic syndrome was defined according to the ATP III criteria [24].

\section{Two-Dimensional and Doppler Echocardiography}

Echocardiography was performed with a commercially available ultrasound system (Vivid E9, GE Healthcare). All echocardiographic data were acquired and interpreted by an experienced staff cardiologist (level III training by American Society of Echocardiography standards). Standard, 2-dimensional measurements [end-diastolic and end-systolic LV diameters and volumes, ventricular septum and posterior wall thickness and left atrial (LA) diameters, area and volume] were performed. LA volume was measured using the biplane Simpson's method [25]. LV mass was calculated using the Devereux formula [26]. The LV and LA measurements were indexed by height ${ }^{2.7}$. Echocardiographic LV relative wall thickness (RWT) was measured as: RWT $=2 \times \mathrm{PWTd} /$ LVIDd [27]. Upper normal limits for LV mass index (LVMI) were $51 \mathrm{~g} / \mathrm{m}^{2.7}$ [28]. A cut-off value of 0.42 for RWT was used [25]. We evaluated the patterns of LV remodeling, according to the values of end-diastolic RWT and LVMI as follows: concentric remodeling - elevated RWT with normal LVMI, eccentric hypertrophy elevated LVMI with normal RWT, concentric hypertrophy - both LVMI and RWT elevated [25]. LV ejection fraction (LVEF) was assessed using the Simpson's biplane method. LV diastolic function was evaluated by mitral inflow pulsed-wave Doppler and pulsed-wave tissue Doppler imaging [29]; the latter was carried out in the four-chamber view at the septal mitral annular level. The following parameters were recorded: peak velocity of transmitral flow in early diastole (E), the early diastolic peak myocardial velocity (e') and the E/e' ratio. 
Table 1. Demographic and clinical characteristics of morbidly obese and superobese patients

\begin{tabular}{lccc}
\hline Parameters & Morbidly obese patients $(\mathrm{n}=160)$ & Superobese patients $(\mathrm{n}=38)$ & $\mathrm{p}$ value \\
\hline Age, years & $48 \pm 14$ & $46 \pm 11$ & 0.41 \\
Gender (M:F), $\mathrm{n}$ & $45(28.1): 115(71.9)$ & $13(34.2): 25(65.8)$ & 0.58 \\
Smoking, n & $21(13.1)$ & $6(15.7)$ & 0.86 \\
Metabolic syndrome, $\mathrm{n}$ & $89(55.9)$ & $22(57.8)$ & 0.94 \\
Hypertension, $\mathrm{n}$ & $96(60)$ & $21(55.2)$ & 0.72 \\
Diabetes mellitus, $\mathrm{n}$ & $24(15.2)$ & $6(15.8)$ & 0.89 \\
Dyslipidemia, $\mathrm{n}$ & $90(56.2)$ & $18(47.4)$ & 0.25 \\
Waist circumference, cm & $125.5 \pm 15.1$ & $141.5 \pm 12$ & $<0.001$ \\
BMI, kg/m & $43.9 \pm 2.8$ & $55.6 \pm 5.2$ & $<0.001$ \\
Weight, kg & $120.3 \pm 17.2$ & $155.0 \pm 22.7$ & $<0.001$ \\
Height, cm & $165.3 \pm 9.9$ & $167.2 \pm 10.9$ & 0.29 \\
Heart rate, bpm & $74.1 \pm 11.9$ & $75.8 \pm 10.7$ & 0.42 \\
Systolic BP, mm Hg & $142.6 \pm 17.2$ & $140.6 \pm 17.9$ & 0.52 \\
Diastolic BP, mm Hg & $88.1 \pm 12.6$ & $88.8 \pm 10.2$ & 0.75 \\
Total cholesterol, mg/dl & $206.6 \pm 40.4$ & $212 \pm 54.5$ & 0.49 \\
HDL-cholesterol, mg/dl & $49.1 \pm 13.4$ & $46.2 \pm 11.4$ & 0.22 \\
LDL-cholesterol, mg/dl & $127.3 \pm 36.7$ & $135.7 \pm 43.9$ & 0.22 \\
Triglycerides, mg/dl & $153.2 \pm 72.4$ & $149.8 \pm 70.7$ & 0.79 \\
Glucose, mg/dl & $109.2 \pm 31.5$ & $110.3 \pm 24.3$ & 0.78 \\
HOMA-IR & $7.3 \pm 6.5$ & $9.7 \pm 7.3$ & 0.047 \\
Insulin resistance, $\mathrm{n}$ & $110(68.7)$ & $32(84.2)$ & 0.020 \\
\hline Treatment & & & 0.053 \\
Statin, $\mathrm{n}$ & $15(9.4)$ & $2(5.3)$ & 0.61 \\
ACE inhibitors, $\mathrm{n}$ & $22(13.7)$ & $4(10.5)$ & 0.043 \\
ARBs, $\mathrm{n}$ & $47(29.4)$ & $5(13.2)$ & 0.12 \\
Beta-blockers, $\mathrm{n}$ & $35(21.9)$ & $4(10.5)$ & \\
\hline
\end{tabular}

Data are reported as mean \pm standard deviation for continuous variables and as percentage for categorical variables. All figures in parentheses are percentages. ACE = Angiotensin-converting-enzyme; ARBs = angiotensin receptor blockers; $\mathrm{BP}=$ blood pressure.

The interobserver and intraobserver variability for standard measurements in our laboratory was previously reported to be optimal [30].

\section{Assessment of Insulin Resistance}

The Homeostasis Model Assessment of insulin resistance (HOMA-IR) index was calculated as [fasting insulin $(\mathrm{mU} / \mathrm{l}) \times$ fasting glucose $(\mathrm{mmol} / \mathrm{l})] / 22.5[31]$.

\section{Statistical Analysis}

Patients were divided into 2 groups according to the BMI: morbidly obese (BMI $\geq 40$ and $<50$ ) and superobese (BMI $\geq 50)$. The characteristics of the groups are presented as mean \pm standard deviation for continuous variables, since they were normally distributed, and as percentages for categorical variables. The $\chi^{2}$ test was used for the comparison of dichotomous variables, and the Student $t$ test for continuous variables. The relationship between BMI and the 2-dimensional and Doppler echocardiographic parameters was evaluated by linear regression analysis. Values of $\mathrm{p}<0.05$ were considered statistically significant. Data analysis was performed using SPSS for Windows, version 13.0 (SPSS Inc., Chicago, Ill., USA).

\section{Results}

The demographic and clinical characteristics of patients are presented in table 1. Age was similar between the 2 groups (morbidly obese: $46 \pm 11$ vs. superobese: $48 \pm 14$ years, $p=0.41$ ). There was a higher prevalence of females in both groups but no significant gender difference between groups $(p=0.58)$. Superobese patients had significantly higher values of HOMA-IR than morbidly obese patients $(9.7 \pm 7.3$ vs. $7.3 \pm 6.5, p=0.047)$. LDL-cholesterol levels showed a trend to increase, while the HDL-cholesterol values decreased across the 2 groups, but these differences did not reach statistical significance. Blood pressure values and glucose levels were similar between the 2 groups, as well as the prevalence of hypertension.

The echocardiographic characteristics of the 2 groups are shown in table 2 . The overall mean LVEF was $61 \pm 4 \%$ 
Table 2. Echocardiographic characteristics in morbidly obese and superobese patients

\begin{tabular}{lccc}
\hline Parameters & $\begin{array}{l}\text { Morbidly } \\
\text { obese patients } \\
(\mathrm{n}=160)\end{array}$ & $\begin{array}{l}\text { Superobese } \\
\text { patients } \\
(\mathrm{n}=38)\end{array}$ & $\begin{array}{l}\mathrm{p} \\
\text { value }\end{array}$ \\
\hline LVDd, cm & $5.0 \pm 0.4$ & $5.2 \pm 0.5$ & 0.009 \\
LVDs, cm & $3.2 \pm 0.4$ & $3.4 \pm 0.4$ & 0.006 \\
IVSd, cm & $1.2 \pm 0.1$ & $1.3 \pm 0.2$ & $<0.001$ \\
LVPWd, cm & $1.1 \pm 0.1$ & $1.2 \pm 0.1$ & $<0.001$ \\
LVED volume index, $\mathrm{ml} / \mathrm{m}^{2.7}$ & $31.5 \pm 7.1$ & $33.8 \pm 7.7$ & 0.041 \\
LVES volume index, $\mathrm{ml} / \mathrm{m}^{2.7}$ & $10.9 \pm 2.8$ & $12.2 \pm 3.6$ & 0.016 \\
LVMI, g/m ${ }^{2.7}$ & $59.9 \pm 11.9$ & $66.0 \pm 14.7$ & 0.007 \\
RWT & $0.45 \pm 0.1$ & $0.50 \pm 0.1$ & 0.58 \\
LVEF, \% & $61.2 \pm 4.3$ & $60.2 \pm 3.5$ & 0.18 \\
LAVI, $\mathrm{ml} / \mathrm{m}^{2.7}$ & $12.2 \pm 3.9$ & $13.8 \pm 4.5$ & 0.029 \\
E/e' & $8.2 \pm 2.2$ & $9.1 \pm 2.6$ & 0.030 \\
\hline
\end{tabular}

IVSd = End-diastolic interventricular septal thickness; LVPWd = end-diastolic left ventricular posterior wall thickness; LVDd = end-diastolic left ventricular diameter; LVDs = end-systolic left ventricular diameter; LVED = end-diastolic left ventricular volume; LVES = end-systolic left ventricular volume. Data are reported as mean \pm standard deviation.

and the mean LVMI was $61 \pm 12.7 \mathrm{~g} / \mathrm{m}^{2.7}$. Both diastolic and systolic LV diameters were significantly higher in superobese patients. They also had significantly higher LV end-diastolic and end-systolic volume indices and LVMI $(\mathrm{p}=0.007)$ than morbidly obese patients. The LV mass and LV and LA volumes remained significantly higher in superobese patients than in morbidly obese ones when these cardiac parameters were indexed by height ${ }^{2.7}$ as well. The RWT was similar in the 2 groups. All patients had LV hypertrophy. There was a greater prevalence of concentric LV hypertrophy in both groups (65.6\% in morbidly obese patients and $68.4 \%$ in superobese patients, $p=0.06$ ) and the LV remodeling patterns were similar.

Considering the overall population, we evaluated the relationship between LVMI and BMI. LV mass/height ${ }^{2.7}$ increases consistently and significantly as BMI increases. However, the increase in LVMI is more pronounced in obese patients with hypertension than in those without. We also found a significant correlation between systolic and diastolic blood pressure and LV mass $(\mathrm{r}=0.14, \mathrm{p}<$ 0.001 and $\mathrm{r}=0.17, \mathrm{p}=0.023$ respectively). HOMA-IR and glucose levels did not correlate with LV mass.

LVEF was similar in both groups. LV filling pressures, estimated from the E/e' ratio, were higher in superobese patients $(9.1 \pm 2.6$ vs. $8.2 \pm 2.2, \mathrm{p}=0.030)$.

Cardiac Structure and Function in

Morbid Obesity
LA volume index (LAVI) was larger in superobese patients $(\mathrm{p}=0.029)$.

We found a statistically significant relationship between BMI and LV end-diastolic volume index $(r=0.264$, $\mathrm{p}<0.001)$ (fig. 1a), LV end-systolic volume $(\mathrm{r}=0.282$, $\mathrm{p}<$ $0.001)$ (fig. 1b) and LVMI ( $\mathrm{r}=0.245, \mathrm{p}<0.001)$ (fig. 1c). We found no significant relationship between BMI and ejection fraction (fig. 1d). There was a direct significant correlation of BMI with LAVI $(\mathrm{r}=0.173, \mathrm{p}=0.020)$ (fig. 1e) and with $E / e^{\prime}$ ratio $(r=0.141, p=0.045)$ (fig. 1f).

\section{Discussion}

The main findings of our study are: (1) BMI is significantly related to cardiac structure and LV diastolic function changes, also in morbidly obese patients, (2) increasing levels of obesity are associated with concentric LV hypertrophy rather than eccentric LV hypertrophy in both morbidly obese and superobese patients and (3) superobese patients have significantly higher insulin resistance than morbidly obese ones.

Although several recent studies have reported cardiac remodeling and LV systolic and diastolic dysfunction in obese patients, little is known about the impact of superobesity on cardiac geometry and function. Different results have been published concerning LV remodeling and geometry in obesity. In 1983, Messerli et al. [32] showed that obesity is associated with eccentric LV hypertrophy, attributable to the predominance of the obesity-related volume overload. Recent data challenge this paradigm. Lavie et al. [33] evaluated LV geometry in a large population of obese subjects with preserved LVEF, and found that concentric LV remodeling was the most prevalent abnormal pattern (34\%), with concentric and eccentric LV hypertrophy occurring only in 8 and 7\%, respectively. To evaluate LV mass in obese subjects, it has been suggested that indexing to height ${ }^{2.7}$ may be more appropriate than normalization for body surface area or even for height alone $[34,35]$. Woodiwiss et al. [36], in a series of 309 obese subjects, showed that LV concentric remodeling and hypertrophy, using LV mass indexed for height ${ }^{2.7}$, were more prevalent than eccentric hypertrophy. They also demonstrated that waist circumference was related to both LV wall thickness and RWT, independent of blood pressure. In a recent study, Aurigemma et al. [11] showed that cardiac remodeling in obesity is characterized by concentric geometry at least as often as eccentric geometry. They also reported subclinical abnormalities in myocardial function and dia- 


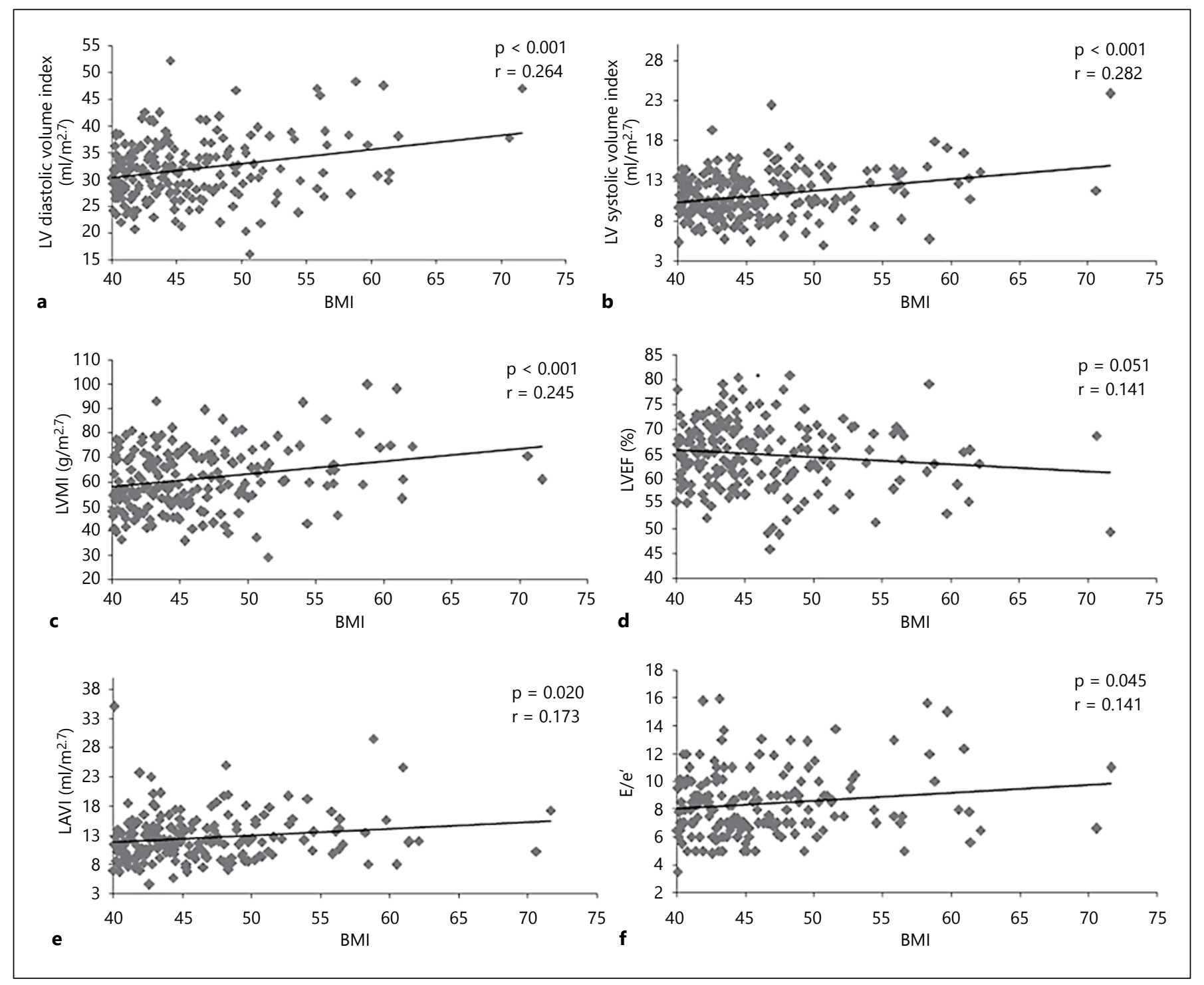

Fig. 1. a Linear correlation between BMI and LV end-diastolic volume index. b Linear correlation between BMI and LV end-systolic volume index. c Linear correlation between BMI and LVMI. There is a statistically significant relationship between BMI and LVMI. d Lin- ear correlation between BMI and LVEF. We observe a lack of relationship between LVEF and BMI. Even at the highest levels of BMI, the average LVEF remains normal. e Linear correlation between BMI and LAVI. $\mathbf{f}$ Linear correlation between BMI and E/e' ratio. stolic filling in obese patients. In our study, changes in LV geometry tended toward concentric rather than eccentric LV hypertrophy among both morbidly obese and superobese patients. We also found a significant relationship between BMI and LVMI in the whole study group.

Obesity is an independent risk factor for arterial hypertension [37]. When the two coexist, there is a substantial increase in the prevalence of LV hypertrophy [38,39]. In our study, we found that as BMI increases, there is a significant increase in LVMI and that this is more pronounced in obese patients with hypertension than in those without.

Several studies showed that weight loss is associated with reduction of LV hypertrophy in obese individuals [40, 41]. Owan et al. [42] confirmed the effect of weight loss on reduction of LV mass in obese patients who underwent bariatric surgery. The mechanisms of improvement of LV geometry with weight loss appear to be primarily hemodynamic. 
Studies have shown that concentric LV geometry is associated with LA remodeling [43]. In this study, LAVI was significantly higher in superobese patients.

Powell et al. [44] have shown that there is no clear relationship between BMI and LVEF and that LVEF can be normal even in patients with $\mathrm{BMI} \geq 40$. We found no correlation between BMI and LVEF, which was normal in both morbidly obese and superobese patients, confirming previous findings.

The majority of studies looking at LV diastolic filling in obesity showed mild abnormalities. The continuous relationship between $\mathrm{BMI}$ and the $\mathrm{E} / \mathrm{e}^{\prime}$ ratio suggests that obese individuals with a large prevalence of other major risk factors have higher LA pressures at rest [45]. The increased LV filling pressures are consistent with an association between LV dysfunction and obesity [46]. In addition, despite a narrow range of very high BMI values, we were able to find a significant relationship between $\mathrm{BMI}$ and $\mathrm{E} / \mathrm{e}^{\prime}$ ratio, which was higher in superobese patients than in morbidly obese patients.

Most studies of LV remodeling in obesity have been performed with 2-dimensional echocardiography, generally a suitable technique for the assessment of cardiac structure and function in obese patients. Other imaging modalities like cardiac magnetic resonance (CMR) have been shown to be accurate and reproducible for the assessment of ventricular size and function [47]. Using CMR imaging, Rider et al. [48] evaluated the main predictors of LV mass in severely obese subjects free of additional cardiovascular risk factors. They found that lean body mass, visceral fat mass and stroke volume had a statistically significant independent association with LV mass, suggesting that all these factors play an important role in determining LV mass in uncomplicated obesity. Turkbey et al. [49] evaluated the relationship of LV remodeling, assessed by CMR, to various measures of obesity in a large multiethnic cohort study. Similar to our findings, they reported that obesity was associated with concentric LV remodeling without a change in LVEF. They found a significant correlation between BMI and the LV mass/volume ratio, a 3-dimensional measure of concentric geometry of the LV.

To our knowledge, until now, very few studies have assessed the impact of superobesity on LV and LA geometry and function. Iacobellis et al. [22] evaluated cardiac structure and function in a small series of uncomplicated severely obese subjects. They reported that severely obese patients with BMI $>50$ had a greater LVMI than normalweight subjects, but found no significant difference in LVMI between severe obesity (with BMI $\geq 50$ ) and 'sim-

Cardiac Structure and Function in

Morbid Obesity ple' obesity (BMI $<50)$. This may have been due to the small number of patients in their study.

We found the superobese patients were more insulin-resistant, as estimated by HOMA-IR, than the morbidly obese ones. Insulin resistance is typically defined as a condition of diminished ability of target tissues to take up and metabolize glucose in response to insulin. Insulin resistance is also a key feature of a spectrum of metabolic abnormalities such as obesity and glucose intolerance, and is associated with multiple cardiovascular risk factors [50]. Hyperinsulinemia and insulin resistance, which are closely related to obesity, may induce myocardial hypertrophy via a growth-stimulating effect of insulin or by increasing blood volume [51]. This association has vast implications and calls for intensive investigation of the causes of the disease in order to optimize its treatment and to possibly prevent its onset.

Our study has some limitations. The main one is that it is a retrospective, observational study. Echocardiography can be technically difficult in morbidly obese patients; however, it is a suitable technique for the assessment of cardiac structure and function in obesity. Moreover, patients with a suboptimal acoustic window were specifically excluded from the study. The use of echocardiography was important as it is ubiquitous, safe, fast and less costly than CMR. Furthermore, CMR may be difficult to use in severely obese subjects due to the confining size of the bore on most modern CMR units. We used standard BMI-recognized cut-off points to define obesity that may be less valid. We did not measure the body fat or body composition to reflect adiposity. When assessing the cardiac remodeling in morbid obesity, our study did not take into account the presence, severity and duration of arterial hypertension in relation to the severity and duration of obesity. Another limitation is that we did not assess variables that might influence LV structure and function such as leptin and enhanced sympathetic nervous system activation.

\section{Conclusion}

The results of this study indicate that superobesity is associated with a worse impact on cardiac remodeling, LV diastolic dysfunction and insulin resistance than simple morbid obesity. Given the increasing prevalence of superobesity, determining these subtle changes is valuable. If LV remodeling precedes LV dysfunction, identification of structural and functional abnormalities in su- 
perobesity may support a stronger argument for counseling with regard to weight loss in these patients, as they already have evidence of heart disease. It is necessary to gain a deeper understanding of how superobesity affects the heart and modulates the cardiovascular responses to lifestyle changes, surgical interventions and pharmacotherapies. Prospective studies are needed to evaluate whether adding a class IV to the current definition of obe- sity, in order to define superobesity (BMI $\geq 50$ ), could stratify the cardiovascular risk in these patients more accurately.

\section{Disclosure Statement}

The authors have no conflicts of interest to disclose.

\section{References}

$\checkmark 1$ Ogden CL, Carroll MD, Curtin LR, McDowell MA, Tabak CJ, Flegal KM: Prevalence of overweight and obesity in the United States, 19992004. JAMA 2006;295:1549-1555.

2 Casazza K, Fontaine K, Astrup A, Birch L, Brown A, Brown M, et al: Presumptions and facts about obesity. N Engl J Med 2013;368: 446-454.

- 3 De Simone G, Devereux RB, Mureddu GF, Roman MJ, Ganau A, Alderman MH, et al: Influence of obesity on left ventricular midwall mechanics in arterial hypertension. Hypertension 1996;28:276-283.

4 Flegal K, Carroll M, Kit B, Ogden C: Prevalence of obesity and trends in the distribution of body mass index among US adults, 19992010. JAMA 2012;307:491-497.

5 Sturm R: Increases in morbid obesity in the USA, 2000-2005. Public Health 2007;121: 492-496.

-6 Lavie CJ, Milani RV, Ventura HO: Obesity and cardiovascular disease: risk factor, paradox and impact of weight loss. J Am Coll Cardiol 2009;53:1925-1932.

7 Cepeda-Valery B, Pressman GS, Figueredo VM, Romero-Corral A: Impact of obesity on total and cardiovascular mortality - fat or fiction? Nat Rev Cardiol 2011;8:233-237.

8 Murphy NF, MacIntyre K, Stewart S, Hart CL, Hole D, McMurray JJ: Long-term cardiovascular consequences of obesity: 20 -year followup of more than 15,000 middle-aged men and women (the Renfrew-Paisley study). Eur Heart J 2006;27:96-106.

-9 Poirier P, Giles TD, Bray GA, Hong Y, Stern JS, Pi-Sunyer FX, et al: Obesity and cardiovascular disease: pathophysiology, evaluation and effect of weight loss: an update of the 1997 American Heart Association Scientific Statement on Obesity and Heart Disease from the Obesity Committee of the Council on Nutrition, Physical Activity and Metabolism. Circulation 2006;113:898-918.

10 Litwin SE: Cardiac remodeling in obesity: time for a new paradigm. J Am Coll Cardiol Cardiovasc Imaging 2010;3:275-277.

-11 Aurigemma GP, de Simone G, Fitzgibbons TP: Cardiac remodeling in obesity. Circ Cardiovasc Imaging 2013;6:142-152.

12 Bella JN, Devereux RB, Roman MJ, O’Grady MJ, Welty TK, Lee ET, et al, the Strong Heart
Study Investigators: Relations of left ventricular mass to fat-free and adipose body mass: the Strong Heart Study. Circulation 1998;98: 2538-2544.

13 de Simone G, Devereux RB, Kizer JR, Chinali M, Bella JN, Oberman A, et al: Body composition and fat distribution influence systemic hemodynamics in the absence of obesity: the HyperGEN Study. Am J Clin Nutr 2005;81: 757-761.

14 Collis T, Devereux RB, Roman MJ, de Simone G, Yeh J, Howard BV, et al: Relations of stroke volume and cardiac output to body composition: the Strong Heart Study. Circulation 2001;103:820-825.

15 Warnes CA, Roberts WC: The heart in massive obesity: analysis of 12 patients studied at necropsy. Am J Cardiol 1984;54:1087-1091.

16 Vasan RS: Cardiac function and obesity. Heart 2003;89:1127-1129.

17 Di Bello V, Santini F, Di Cori A, Pucci A, Palagi C, Delle Donne MG, et al: Relationship between preclinical abnormalities of global and regional left ventricular function and insulin resistance in severe obesity: a Color Doppler Imaging Study. Int J Obes 2006;30: 948-956.

18 Reaven G: Insulin resistance: the link between obesity and cardiovascular disease. Med Clin North Am 2011;95:875-892.

19 Mason EE, Doherty C, Maher JW, Scott DH, Rodriguez EM, Blommers TJ: Super obesity and gastric reduction procedures. Gastroenterol Clin North Am 1987;6:495-502.

20 Schroeder R, Garrison JM, Johnson S: Treatment of adult obesity with bariatric surgery. Am Fam Physician 2011;84:805-814.

21 Kral JG: Morbidity of severe obesity. Surg Clin North Am 2001;81:1039-1061.

22 Iacobellis G, Ribaudo MC, Zappaterreno A, Iannucci CV, Di Mario U, Leonetti F: Adapted changes in left ventricular structure and function in severe uncomplicated obesity. Obes Res 2004;12:1616-1621.

23 Friedewald WT, Levy RI, Fredrickson DS: Estimation of the concentration of low-density lipoprotein cholesterol in plasma without use of the preparative ultracentrifuge. Clin Chem 1972;18:499-502.

24 Grundy SM, Brewer HB Jr, Cleeman JI, Smith SC Jr, Lenfant C: Definition of metabolic syn- drome: report of the National Heart, Lung, and Blood Institute/American Heart Association conference on scientific issues related to definition. Circulation 2004;109:433-438.

25 Lang RM, Bierig M, Devereux RB, Flachskampf FA, Foster E, Pellikka PA, et al: Recommendations for chamber quantification. Eur $J$ Echocardiogr 2006;7:79-108.

26 Ganau A, Devereux RB, Roman MJ, de Simone G, Pickering TG, Saba PS, et al: Patterns of left ventricular hypertrophy and geometry remodelling in essential hypertension. J Am Coll Cardiol 1992;19:1550-1558.

27 Sjogren AL: Left ventricular wall thickness determined by ultrasound in 100 subjects without heart disease. Chest 1971;60:341-346.

28 de Simone G, Devereux RB, Daniels SR, Koren MJ, Meyer RA, Laragh JH: Effect of growth on variability of left ventricular mass: assessment of allometric signals in adults and children and their capacity to predict cardiovascular risk. J Am Coll Cardiol 1995;25: 1056-1062.

29 Nagueh S, Appleton C, Gillebert T, Marino P, Oh JK, Smiseth A, et al: Recommendations for the evaluation of left ventricular diastolic function by echocardiography. Eur J Echocardiogr 2009;10:165-193.

30 Antonini-Canterin F, Hîrsu M, Popescu BA, Leiballi E, Piazza R, Pavan D, Ginghina C, Nicolosi GL: Stage-related effect of statin treatment on the progression of aortic valve sclerosis and stenosis. Am J Cardiol 2008;102: 738-742.

31 Matthews DR, Hosker JP, Rudenski AS, Naylor BA, Treacher DF, Turner RC: Homeostasis model assessment: insulin resistance and beta-cell function from fasting plasma glucose and insulin concentrations in man. Diabetologia 1985;28:412-419.

32 Messerli FH, Sundgaard-Riise K, Reisin ED, Dreslinski GR, Ventura HO, Oigman W, et al: Dimorphic cardiac adaptation to obesity and arterial hypertension. Ann Intern Med 1983; 99:757-761.

33 Lavie CJ, Milani RV, Ventura HO, Cardenas GA, Mehra MR, Messerli FH: Disparate effects of left ventricular geometry and obesity on mortality in patients with preserved left ventricular ejection fraction. Am J Cardiol 2007;100:1460-1464. 
34 Lauer MS, Anderson KM, Larson MG, Levy D: A new method for indexing left ventricular mass for differences in body size. Am J Cardiol 1994;74:487-491.

-35 de Simone G, Daniels SR, Devereux RB, Meyer RA, Roman MJ, de Divitiis O, et al: Left ventricular mass and body size in normotensive children and adults: assessment of allometric relations and impact of overweight. J Am Coll Cardiol 1992;20:1251-1260.

- 36 Woodiwiss AJ, Libhaber CD, Majane $\mathrm{OH}$, Libhaber E, Maseko M, Norton GR: Obesity promotes left ventricular concentric rather than eccentric geometric remodeling and hypertrophy independent of blood pressure. Am J Hypertens 2008;21:1144-1151.

-37 de Simone G, Devereux RB, Chinali M, Roman MJ, Best LG, Welty TK, et al: Risk factors for arterial hypertension in adults with initial optimal blood pressure: the Strong Heart Study. Hypertension 2006;47:162-167.

-38 Obesity in Asia Collaboration: Is central obesity a better discriminator of the risk of hypertension than body mass index in ethnically diverse populations? J Hypertens 2008;26: 169-177.

39 Avelar E, Cloward TV, Walker JM, Farney RJ, Strong M, Pendleton RC, et al: Left ventricular hypertrophy in severe obesity: interactions among blood pressure, nocturnal hypoxemia, and body mass. Hypertension 2007;49:34-39.
40 Himeno E, Nishino K, Nakashima Y, Kuroiwa A, Ikeda M: Weight reduction regresses left ventricular mass regardless of blood pressure level in obese subjects. Am Heart J 1996;131: 313-319.

41 Alpert MA, Terry BE, Kelly DL: Effect of weight loss on cardiac chamber size, wall thickness and left ventricular function in morbid obesity. Am J Cardiol 1985;55:783786.

42 Owan T, Avelar E, Morley K, Jiji R, Hall N, Krezowski J, et al: Favorable changes in cardiac geometry and function following gastric bypass surgery: 2-year follow-up in the Utah Obesity Study. J Am Coll Cardiol 2011;57: 732-739.

43 Abhayaratna WP, Seward JB, Appleton CP Douglas PS, Oh JK, Tajik AJ, et al: Left atrial size: physiologic determinants and clinical applications. J Am Coll Cardiol 2006;47: 2357-2363.

44 Powell BD, Redfield MM, Bybee KA, Freeman WK, Rihal CS: Association of obesity with left ventricular remodeling and diastolic dysfunction in patients without coronary artery disease. Am J Cardiol 2006;98:116-120.
45 Russo C, Jin Z, Homma S, Rundek T, Elkind MS, Sacco RL, et al: Effect of obesity and overweight on left ventricular diastolic function: a community-based study in an elderly cohort. J Am Coll Cardiol 2011;57:1368-1374.

46 Di Bello V, Santini F, Di Cori A, Pucci A, Palagi C, Delle Donne MG, et al: Obesity cardiomyopathy: is it a reality? An ultrasonic tissue characterization study. JASE 2006;19:1063-1071.

47 Grothues F, Smith GC, Moon JC, Bellenger NG, Collins P, Klein HU, et al: Comparison of interstudy reproducibility of cardiovascular magnetic resonance with two-dimensional echocardiography in normal subjects and in patients with heart failure or left ventricular hypertrophy. Am J Cardiol 2002;90:29-34.

48 Rider OJ, Francis JM, Ali MK, et al: Determinants of Left ventricular mass in obesity: a cardiovascular magnetic resonance study. J Cardiovasc Magn Reson 2009;11:9.

-49 Turkbey EB, McClelland RL, Kronmal RA, Burke GL, Bild DE, Tracy RP, et al: The impact of obesity on the left ventricle: the MultiEthnic Study of Atherosclerosis (MESA). JACC Cardiovasc Imaging 2010;3:266-274.

-50 Ferrannini E, Natali A, Belli P, Cavallo-Perin $\mathrm{P}$, Lalic N, Mingrone G: Insulin resistance and hypersecretion in obesity. J Clin Invest 1997; 100:1166-1173.

51 Abel ED, Litwin SE, Sweeney G: Cardiac remodeling in obesity. Physiol Rev 2008;88: 389-419. 